\title{
A SIMPLE FISCAL RULE FOR HUNGARY*
}

\author{
András BALATONI
}

In this paper, I outline an alternative public debt rule, a basic structure that provides a sufficient reduction of public debt in the long term, with an escape clause ensuring the opportunity for countercyclical budgetary manoeuvring and the avoidance of the so-called ratchet effect. The last section outlines a basic institutional framework. I have raised this topic in the hope of supporting the Hungarian discussion about fiscal rules and perhaps to contribute to it. I am certain that this rule is far from perfect, but I believe it is a good starting point.

Keywords: fiscal policy, fiscal rules, debt, deficit, demand management, Hungary

JEL classification indices: E32, E61, E62

More and more problems arise with the current Hungarian fiscal regulation, but there are hardly any proposals that could provide a solution. For this reason, I decided to present a new debt rule that eliminates the problems of the current framework. Its long-term use will have a positive effect on public finances and their sustainability. Budgetary regulation is much more than a "formula". The institutions, accountability, and the establishment of responsibilities are equally important (if not more) in creating a prudent fiscal policy as the basic formula. Nevertheless,

* The author is grateful to Csaba G. Tóth for his invaluable comments and remarks. I thank to András Hinkel for research assistance. All the reminder failures and mistakes are the responsibility of the author.

András Balatoni, Senior economist at ING Commercial Bank, N.V. Hungary Branch, Financial Market Research. E-mail: andras.balatoni@ingbank.com 
I deal with these issues only superficially in this paper. I introduce a simple rule, which can be easily parameterised, so it can reflect economic policy preferences. Moreover, during and shortly after times of recession, the new rule provides sufficient room for fiscal manoeuvring to stimulate the economy. It also helps to avoid the so-called ratchet effect, which means that during recessions, public indebtedness increases by a greater amount than it decreases in the expansionary phase of the business cycle. It is important to stress that the rule presented here is relatively simple and is not based on the uncertain estimation of the output gap.

\section{ABOUT FISCAL RULES IN GENERAL}

I do not intend to offer a detailed explanation about why we need fiscal rules. Balatoni - Tóth (2012) describe in detail the reasons why governments tend to have a propensity to accumulate debt (problem of the commons, short-term preferences of the policymakers, time inconsistency, etc). The desire of governments for spending has long been with us, market correction is not universal, and - more importantly - may have serious social costs. The institutional solution in this case is designing a fiscal rule system, which, according to Kennedy - Robins (2001), results in increased macroeconomic stability, in improved credibility of the government and its announced debt reduction measures, in a more easily sustainable fiscal policy, and in minimising the externalities in the case of the various levels of government and international community (e.g. over-indebtedness of municipalities, the Greek situation). Rules should therefore exist. But how does a good fiscal rule look like?

The bulk of the literature uses the criteria proposed by Kopits - Symansky (1998) to assess fiscal rules. They defined 8 basic criteria. I will not examine all of them, just the following ones:

1. Does the fiscal rule ensure debt reduction?

2. Does the fiscal rule give adequate room for counter-cyclical budgetary manoeuvres when these are needed?

3. Is the rule able to reflect economic policy preferences?

4. Does the rule make it easy to calculate the budget deficit and assess the stance of fiscal policy?

\section{THE CURRENT HUNGARIAN SITUATION}

The Fundamental Law of Hungary, the country's new constitution adopted in 2011, also deals with debt reduction: GDP-to-debt ratio is to be reduced until it reaches $50 \%$. There are exceptions to this rule such as a state of emergency, or 
permanent and significant decline in the economy. In the Stability Act, the prolonged and significant decline in the economy is defined as follows: "a sustained and significant fall in the economy shall be construed as any case when the real value of the annual gross domestic product declines". Accordingly, the Fundamental Law requires debt reduction already in the first year after the recession, when economic growth is weak and fragile.

The second most important piece of legislation, which has been criticised many times before (Balatoni - Tóth 2012; Baksai - P. Kiss 2013; IMF 2012), is the formula specified in the Stability Act. This formula defines the maximum rate of change of nominal public debt as follows: "in the law about the central budget [the deficit] shall be determined in such a way that growth of the nominal debt compared to the previous year (hereinafter referred to as the reference year) shall not exceed the inflation minus half of the real GDP growth." The Ministry of Finance proposed a change to this rule in mid-2015, which quickly went into effect. Now, the formula enters into force only if both inflation and real economic growth exceed 3\%. In all the other cases, debt-to-GDP has to be reduced at least by 0.1 percentage point year after year.

The third group of fiscal rules seems to be extraneous to the above-mentioned two laws. According to one of these rules, the National Assembly is not allowed to adopt a budget, in which the deficit-to-GDP ratio exceeds $3 \%$, and in which the structural deficit (adjusted by the cyclical factor modifying the potential growth rate, one-off expenditures, and revenues) exceeds the medium-term objective, which is currently $1.7 \%$. It is important to emphasise that at the moment, the EU does not require Hungary to have a regulation for the structural deficit, thus, in my opinion, this rule is only making the framework more complicated and less transparent instead of improving it. Not to mention the fact that the estimation of the potential growth rate and hence the output gap is highly uncertain.

To visualise the legal chaos in the Hungarian fiscal regulation, Table 1 shows the maximum debt-to-GDP level at the end of the year, if the reference year's figure was $76.9 \%$. Table 2 shows the maximum of the deficit ratio. Different shades of black depict the effective regulation (that requires the tightest fiscal policy at a certain level of real GDP growth, and inflation). In the case of recession, the growth of debt-to-GDP ratio is literally unlimited, thus we cannot determine the debt-to-GDP level, or the deficit ratio (marked by ???). In the case of the positive volume change of the GDP, we can define the maximum of the deficit, and the highest level of public debt-to-GDP ratio. When nominal GDP growth does not exceed 4\%, the new regulation is effective: that means that the debt-to-GDP ratio has to decrease by 0.1 percentage point on a yearly basis. This formula is strongly procyclical, since in the case of lower growth and lower inflation it prescribes tighter and tighter fiscal policy. Since the potential GDP growth is roughly $2.5 \%$ 
Table 1. Required debt-to-GDP ratio (\% of GDP) according to the present regulation in the case of different growth/inflation combinations in $\mathrm{t}+1$ period

\begin{tabular}{|c|c|c|c|c|c|c|c|c|c|c|}
\hline & \multicolumn{10}{|c|}{ Inflation (\%) } \\
\hline & 0.5 & 1.0 & 1.5 & 2.0 & 2.5 & 3.0 & 3.5 & 4.0 & 4.5 & 5.0 \\
\hline-1 & $? ? ?$ & $? ? ?$ & $? ? ?$ & $? ? ?$ & $? ? ?$ & $? ? ?$ & $? ? ?$ & $? ? ?$ & $? ? ?$ & $? ? ?$ \\
\hline-0.5 & $? ? ?$ & $? ? ?$ & $? ? ?$ & $? ? ?$ & $? ? ?$ & $? ? ?$ & $? ? ?$ & $? ? ?$ & $? ? ?$ & $? ? ?$ \\
\hline 2 & 76.8 & 76.8 & 76.8 & 76.8 & 76.8 & 76.8 & 76.8 & 76.9 & 76.6 & 76.2 \\
\hline 0.5 & 76.8 & 76.8 & 76.8 & 76.8 & 76.8 & 76.8 & 76.8 & 76.6 & 76.2 & 75.9 \\
\hline$\underline{\Xi}$ & 76.8 & 76.8 & 76.8 & 76.8 & 76.8 & 76.8 & 76.6 & 76.2 & 75.9 & 75.5 \\
\hline 1.5 & 76.8 & 76.8 & 76.8 & 76.8 & 76.8 & 76.6 & 76.2 & 75.8 & 75.5 & 75.2 \\
\hline วิ & 76.8 & 76.8 & 76.8 & 76.8 & 76.6 & 76.2 & 75.8 & 75.5 & 75.1 & 74.8 \\
\hline 2.5 & 76.8 & 76.8 & 76.8 & 76.6 & 76.2 & 75.8 & 75.5 & 75.1 & 74.8 & 74.5 \\
\hline$\stackrel{\circ}{=}$ & 76.8 & 76.8 & 76.6 & 76.2 & 75.8 & 75.5 & 75.1 & 74.8 & 74.4 & 74.1 \\
\hline 3.5 & 76.8 & 76.6 & 76.2 & 75.8 & 75.5 & 75.1 & 73.0 & 73.0 & 73.1 & 73.1 \\
\hline छ் & 76.6 & 76.2 & 75.8 & 75.5 & 75.1 & 74.8 & 72.5 & 72.5 & 72.5 & 72.5 \\
\hline 4.5 & 76.2 & 75.9 & 75.5 & 75.1 & 74.8 & 74.4 & 72.0 & 72.0 & 72.0 & 72.0 \\
\hline 5 & 75.9 & 75.5 & 75.2 & 74.8 & 74.5 & 74.1 & 71.5 & 71.5 & 71.5 & 71.5 \\
\hline IC & & & & & & & & & ld & \\
\hline
\end{tabular}

Notes: I did not take the structural deficit rule into consideration, since in that case, I would have had to take the output gap also into consideration. Debt-to-GDP ratio in period $t=76.9$.

Source: Author's calculation.

in Hungary (MNB 2014) while the inflation target is at 3\%, this regulation will be effective only temporarily.

If nominal GDP growth is higher than $4 \%$, but GDP volume growth or inflation fail to exceed $3 \%$, the $3 \%$ deficit threshold will be the bottleneck for fiscal stance. With the present potential GDP outlook and CPI targets, this rule will be in effect most of the time. When both the GDP growth and the inflation exceed $3 \%$, then the old formula steps ahead, and it will determine the deficit target.

What is the problem with the current regulation? First of all, the risk of the so-called ratchet effect is high. The ratchet effect means that even though the debt is reduced during high GDP growth periods, when GDP drops, policymakers allow a relatively too big rise in the debt ratio, thus it will show an upward trend in the long run.

The second problem is that the rules imply a strongly procyclical fiscal stance in the case of less than $4 \%$ nominal GDP growth. In the case of "high inflation high growth", the old rule can turn on, which might cool down the economy, but the further rise of inflation can offset this positive effect. To sum up, the present regulation allows the ratchet effect, in most of the cases it is procyclical and really complicated. 
Table 2. Required deficit ratio (\% of GDP) according to the present regulation in the case of different growth/inflation combinations in $\mathrm{t}+1$ period

\begin{tabular}{|c|c|c|c|c|c|c|c|c|c|c|}
\hline & \multicolumn{10}{|c|}{ Inflation (\%) } \\
\hline & 0.5 & 1.0 & 1.5 & 2.0 & 2.5 & 3.0 & 3.5 & 4.0 & 4.5 & 5.0 \\
\hline-1 & $? ? ?$ & $? ? ?$ & $? ? ?$ & $? ? ?$ & $? ? ?$ & ??? & ??? & ??? & ??? & ??? \\
\hline-0.5 & ??? & ??? & ??? & $? ? ?$ & $? ? ?$ & $? ? ?$ & $? ? ?$ & $? ? ?$ & ??? & $? ? ?$ \\
\hline 0 & 0.3 & 0.7 & 1.0 & 1.4 & 1.8 & 2.1 & 2.5 & 3.0 & 3.0 & 3.0 \\
\hline 0.5 & 0.7 & 1.0 & 1.4 & 1.8 & 2.1 & 2.5 & 2.9 & 3.0 & 3.0 & 3.0 \\
\hline 1 & 1.0 & 1.4 & 1.8 & 2.2 & 2.5 & 2.9 & 3.0 & 3.0 & 3.0 & 3.0 \\
\hline 1.5 & 1.4 & 1.8 & 2.2 & 2.5 & 2.9 & 3.0 & 3.0 & 3.0 & 3.0 & 3.0 \\
\hline 2 & 1.8 & 2.2 & 2.5 & 2.9 & 3.0 & 3.0 & 3.0 & 3.0 & 3.0 & 3.0 \\
\hline 2.5 & 2.1 & 2.5 & 2.9 & 3.0 & 3.0 & 3.0 & 3.0 & 3.0 & 3.0 & 3.0 \\
\hline 3 & 2.5 & 2.9 & 3.0 & 3.0 & 3.0 & 3.0 & 3.0 & 3.0 & 3.0 & 3.0 \\
\hline 3.5 & 2.9 & 3.0 & 3.0 & 3.0 & 3.0 & 3.0 & 1.3 & 1.6 & 2.0 & 2.3 \\
\hline 4 & 3.0 & 3.0 & 3.0 & 3.0 & 3.0 & 3.0 & 1.1 & 1.4 & 1.8 & 2.1 \\
\hline 4.5 & 3.0 & 3.0 & 3.0 & 3.0 & 3.0 & 3.0 & 0.9 & 1.2 & 1.6 & 1.9 \\
\hline 5 & 3.0 & 3.0 & 3.0 & 3.0 & 3.0 & 3.0 & 0.7 & 1.1 & 1.4 & 1.7 \\
\hline & & & & & & & & & & \\
\hline
\end{tabular}

Note: I did not take the structural deficit rule into consideration, since in that case, I would have had to take the output gap also into consideration. Debt-to-GDP ratio in period $\mathrm{t}=76.9$.

Source: Author's calculation.

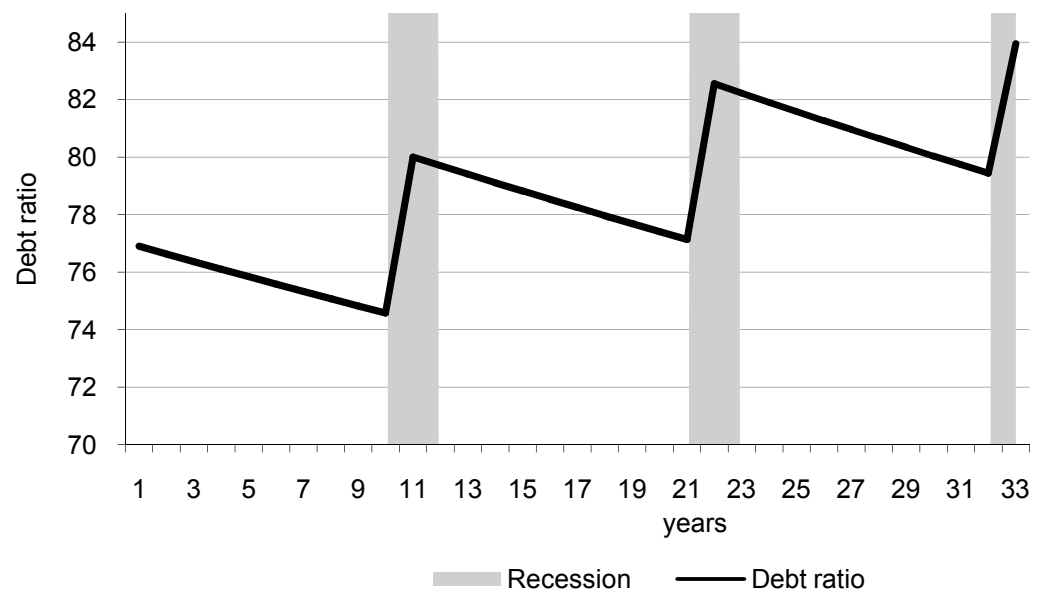

Figure 1. The ratchet effect on the debt ratio, if the debt ratio is not controlled during recessions Source: Author's calculation. 


\section{THE PROPOSED FISCAL RULE}

The complete rule that I recommend can be summarised as follows: "In the law on the central budget, the size of the deficit shall be determined in such a way, that at the end of the calendar year, the debt-to-GDP ratio (hereinafter called the debt ratio) is equal to the debt ratio of the previous year multiplied by one minus the nominal GDP growth rate plus 2.5. If real GDP is expected to fall next year, then the rule will be complemented by a correction factor, and it shall remain in force until the debt ratio reaches the debt ratio prior to the recession. This correction factor lets the debt ratio of the current year rise by the percentage difference of the actual real GDP and the real GDP prior to the recession. Putting the correction factor into force is initiated by the government and approved by the Fiscal Council. Based on the macroeconomic forecasts for the given year, the government will examine if the termination of the use of the correction factor is appropriate, and the decision is approved by the Fiscal Council."

The rule can be divided into three basic parts. The first sub-section describes the basic structure of the rule, the second describes the so-called escape enclosure, while the third sub-section clarifies some parts of the necessary institutional conditions.

\subsection{Basic structure}

One of the advantages of this new fiscal rule is its simplicity. Namely, that at the end of the calendar year, the debt ratio is equal to debt ratio of the year-end debt ratio of the previous year multiplied by one minus the nominal GDP growth rate plus 2.5. This relationship is captured by the following formula:

$$
b_{t}=\left(1-\pi_{t}-g_{t}\right) b_{t-1}+2.5,
$$

where $b_{t}$ is the debt ratio at the end of period $\mathrm{t}, \pi_{t}$ is the year-on-year growth of the GDP deflator, while $g_{t}$ is the year-on-year change of the real GDP. In this case, higher nominal growth (regardless of higher real growth or higher GDP deflator) entails a faster debt reduction and smaller deficits. Therefore, the formula provides the appropriate room for a fiscal policy response to the rise in inflation or acceleration in growth. Of course, the extent of the reaction can be and should be subject to debate. And why the 2.5 correction factor? That is because if in the long run we expect a $5.5 \%$ nominal GDP growth $(2.5 \%$ real GDP growth, just like MNB (2014) and 3\% inflation), the 2.5 parameter ensures that the debt ratio is converging to the $45 \%$ level. 


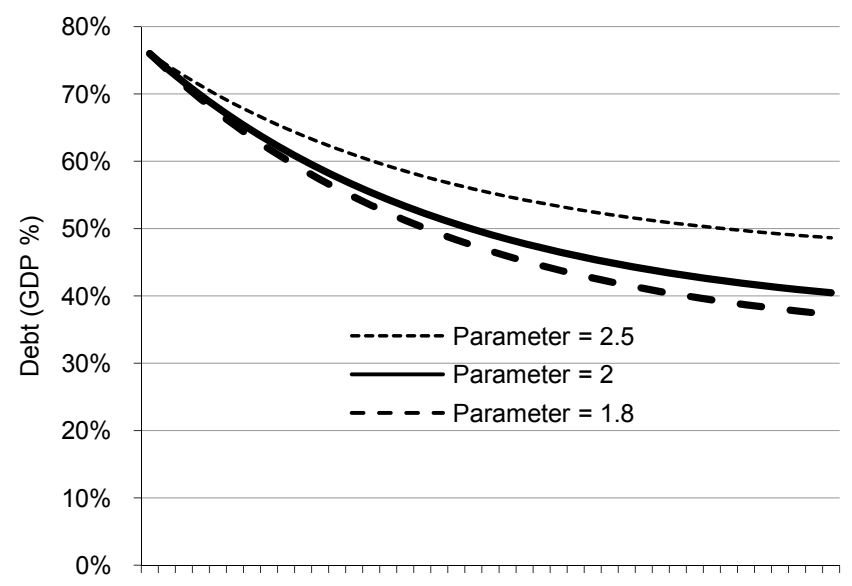

$1 \quad 3 \quad 5 \quad 7 \quad 911131517192123252729313335373941$

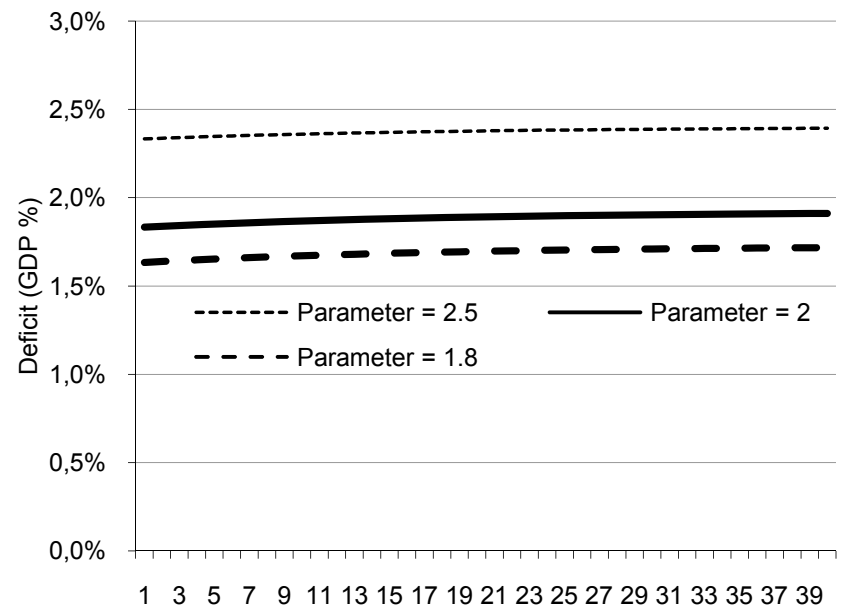

Figure 2. The debt ratio and the deficit at different parameters (years on the horizontal axis) Source: Author's calculation.

This leads us to policy decisions. We can write $2.0,2.5$ or even 1.0 to the formula. This should be decided by the economic policymakers. With the value of this number, we can define the longer term convergence of the debt-to-GDP ratio, but its social burdens should be taken into consideration at the same time. Convergence to a $45 \%$ debt ratio is broadly consistent with the Constitution's requirement of less than $50 \%$ debt ratio and with a deficit of $2.3-2.4 \%$. If we enter the number 2.0 into the formula, then, in the long run, the debt ratio will converge 
to a level below $40 \%$, while it requires a deficit of $1.8-1.9 \%$. With the current medium-term deficit goal $(1.7 \%)$, a parameter of 1.8 would be consistent. This part of the rule can therefore be freely parameterised, the number will reflect the debt reduction ambitions of the decision makers.

\subsection{Escape clause}

My suggested wording of the second component of fiscal rule is as follows: "If real GDP is expected to fall next year, then the rule is complemented by a correction factor, and it shall remain in force until the debt ratio reaches the debt ratio prior to the recession. This correction factor lets the debt ratio of the current year rise by the percentage difference between the actual real GDP and the real GDP prior to the recession."

With this escape clause, the main question is whether it completely replaces off the application of the fiscal rule or merely complements it. Personally, I am arguing for the second solution in order to avoid the ratchet effect. We need fiscal rules even in bad times.

It is important to mention that I do not interpret economic cycles in line with most textbooks, based on the concept of the output gap. This subject and its different approaches are well summarised by Fatás - Mihlov (2014). The mainstream concept of business cycles is based on the real business cycle theory. According to this theory, the economic output is fluctuating around its equilibrium trend level and random factors (statistical disturbances, noise) distract the GDP from its hypothetical equilibrium state. Even if this theoretical framework is correct, the experience of the recent years clearly demonstrated that there is a huge margin of uncertainity in the calculations.

My rule is based on a much older and simpler concept of the economic cycle, created by Burns - Mitchell (1946) at the dawn of economic cycle research. This concept is based on local minimums and maximums of the real GDP, thus it is not necessary to estimate a trend in this framework. Sections may be examined between troughs and peaks, namely the expansions phases, and between peaks and troughs, namely the recession phases. The frequency of the occurrence of these phases, their duration, the time between peaks, etc., can be analysed. Something quite similar is done by the NBER business cycles dating committee. In contrast to the output gap, the peaks and troughs of economic output can be clearly identified, and the phases of the economic cycle defined in this way are more easily distinguishable from each other. 
If the escape enclosure clause enters into force, the basic formula is changed in the following way:

$$
b_{t}=\left(1-\pi-g_{t}\right) b_{t-1}+2.5-\left(\frac{G D P_{t}}{G D P_{\text {peak }}} * 100-100\right),
$$

where $G D P_{t}$ represents the real GDP of the $\mathrm{t}^{\text {th }}$ period, and $G D P_{\text {peak }}$ represents the real GDP of the pre-recession year. Let's look at this through an example! Let us assume that real GDP increases by $2.5 \%$ during a period of two years, followed by a $5 \%$ recession. Then real GDP grows by $1 \%$ and $1.5 \%$, after which the growth of real GDP returns to its trend of $2.5 \%$. The inflation during the recession is constantly at $3 \%$. If we insert the 2.5 parameter into the basic formula, in the first two years the deficit will be $2.3 \%$. During the recession (starting in the $3^{\text {rd }}$ year) the deficit increases and it exceeds $7 \%$. As the economy recovers after the recession, the deficit gradually decreases. However, as long as the volume of GDP is below the pre-crisis level (in our example it is the $6^{\text {th }}$ year), deficit exceeds the $2.3 \%$ level and the debt ratio is increasing. During this period, it is worth promoting economic growth by more government spending and accommodative fiscal policy. I uphold my statement, even if recessions are often preceded by overheated periods. The economy typically recovers to its pre-crisis levels after 4 or 5 years, so it is worth stimulating the economy during this period even with a very weak supply growth. And why is this so important? Because, even if we pessimistically assume a government expenditure multiplier of 0.5 , we can practically halve the

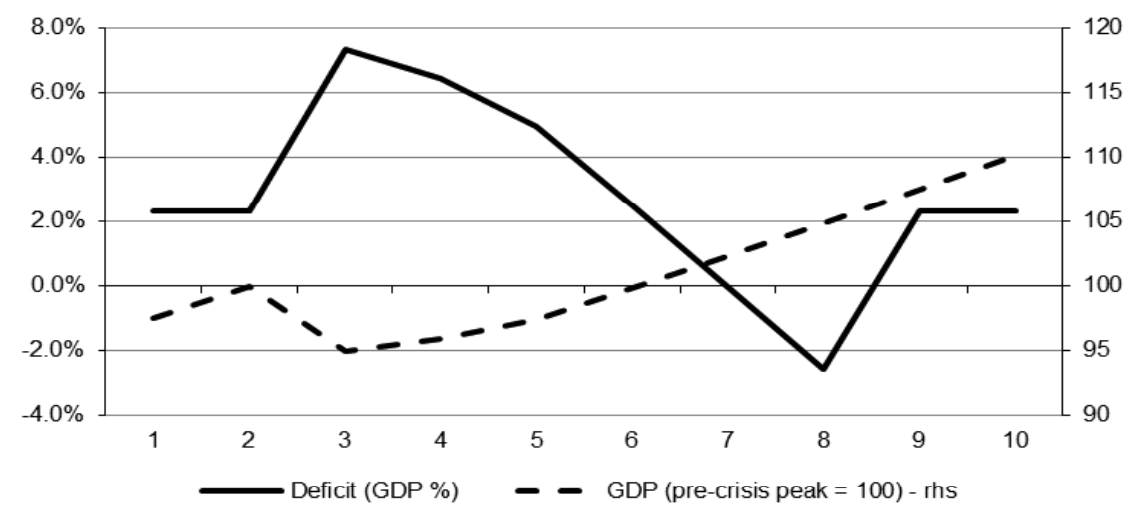

Figure 3. The deficit and the evolution of real GDP during a recession and the subsequent period of weak growth (years on the horizontal axis)

Source: Author's calculation. 


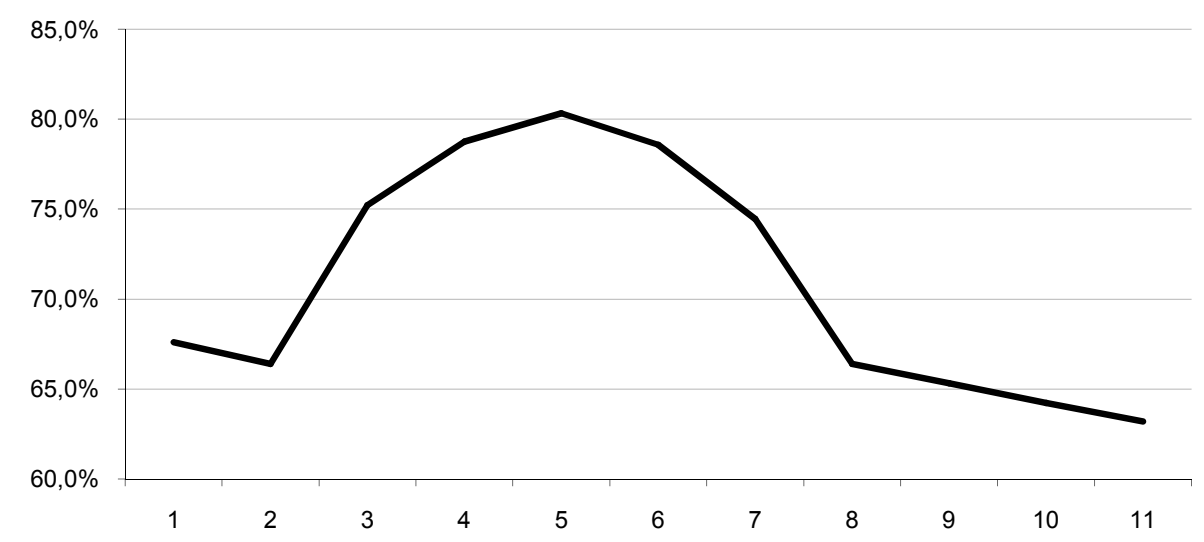

Figure 4. The evolution of the debt ratio during a recession and the subsequent period of weak growth (years on the horizontal axis)

Source: Author's calculation.

rate of economic decline with the counter-cyclical fiscal policy. Of course, during recessions, these multipliers can be much greater according to Blanchard - Leigh (2013), but we should not be so optimistic.

It is important to emphasise that the escape clause does not automatically turn off as real GDP reaches its pre-crisis level. In this case, a faster debt reduction is necessary than in the baseline scenario (the bracketed part in the formula becomes positive), thus the government should adopt a more tight budget than in the baseline scenario. This will ensure that the debt ratio will be lowered to its pre-crisis low point, after which the escape enclosure turns off. In our example, the real GDP in the $6^{\text {th }}$ year reaches its pre-crisis peak, thus deficit is reduced to $2.3 \%$. In the following two years, facilitating a quick debt-reduction, the deficit will be lowered even more. This prevents the emergence of the ratchet effect. In the $9^{\text {th }}$ year, the escape enclosure is switched off, the deficit returns to its natural level, and debt reduction to its normal rate.

\subsection{Institutional background and medium-term planning}

The instituional part of the new fiscal rule can sound as follows: "Putting the correction factor into force is initiated by the government and approved by the Fiscal Council. Based on the macroeconomic forecasts for the given year. The govern- 
ment will examine if the termination of the use of the correction factor is appropriate, and the decision is approved by the Fiscal Council."

It is important to regulate that during the next recession who, in what way, and based on what forecasting will or can give an exemption to the government from its debt lowering obligation. The government on its own, according to the institutional phase of the rule itself, may not decide to put into force the escape clause, or may not decide to terminate it (when it ensures that quick debt reduction). The Fiscal Council is meant to allow the putting into force or the termination of the escape clause, based on macroeconomic projections and medium-term budgetary plans. This institutional safeguard can improve credibility of the fiscal rule.

\section{REFERENCES}

Baksai, G. - P. Kiss, G. (2013): Gondolatok a magyar adósságszabályról (Thoughts about the New Debt Rule of Hungary). MNB Szemle, October.

Balatoni, A. - Tóth, G.Cs. (2012): Az új magyar adósságszabály értékelése (Assessment of the New Debt Rule). Közgazdasági Szemle, LIX(October): 1107-1137.

Blanchard, O. - Leigh, D. (2013): Growth Forecast Errors and Fiscal Multipliers. IMF Working Paper, 13/1.

Burns, A.F. - Mitchell, W.C. (1946): Measuring Business Cycles. New York: NBER.

IMF (2012): Hungary: Country Report. No. 12/13. http://www.imf.org/external/pubs/ft/scr/2012/ cr1213.pdf

Fatas, A. - Mihlov, I. (2013): Recoveries. http://faculty.insead.edu/fatas/Recoveries\%20Fatas\%20 Mihov.pdf

Kennedy, S. - Robbins, J. (2001): The Role of Fiscal Rules in Determining Fiscal Performance. Department of Finance Canada, Working Paper, 2001-16.

Kopits, G. - Symansky, S.A. (1998): Fiscal Policy Rules. IMF Occasional Paper, No. 162.

MNB (2014): Growth Report. Budapest: Magyar Nemzeti Bank. http://www.mnb.hu/Root/Dokumentumtar/MNB/Kiadvanyok/mnbhu_novjel/honlapra_Novekedesi_jelentes_hun_201411.pdf 